\title{
Experimental dataset to develop a parametric model based of DC geared motor in feeder machine
}

\author{
Azlan, W. M. ${ }^{1}$, Salleh, S.M. ${ }^{2}$, Mahzan, S. ${ }^{3}$, Sadikin, A. ${ }^{4}$, Ahmad, S. ${ }^{5}$ \\ 1,3,4,5Faculty of Mechanical and Manufacturing Engineering, Universiti Tun Hussein Onn Malaysia, Malaysia \\ ${ }^{2}$ Mechanical Failure Prevention and Reliability (MPROVE), Department of Engineering Mechanics, Malaysia
}

\begin{tabular}{l} 
Article Info \\
\hline Article history: \\
Received Aug 10, 2018 \\
Revised Nov 20, 2018 \\
Accepted Dec 11, 2018 \\
\hline
\end{tabular}

Keywords:

DC geared motor

Parametric model

Particle swarm optimization

System identification

\begin{abstract}
This paper presents the application of a System Identification based on Particle Swarm Optimization (PSO) technique to develop parametric model of experimental dataset of DC Geared motor in feeder machine. The experimental was conducted to measure the input (voltage) and output (speed) data. The actual data is used to be optimized using PSO algorithm. The parameter emphasized is Time, Man Square Error (MSE) and Average Time. One of the best model has been chosen based on the optimum parameters.
\end{abstract}

Copyright (C) 2019 Institute of Advanced Engineering and Science. All rights reserved.

\section{Corresponding Author:}

Salleh, S.M.,

Department of Engineering Mechanics,

Faculty of Mechanical and Manufacturing Engineering,

101 Pt Raja, Batu Pahat, Johor, Malaysia.

Email: saliha@uthm.edu.my

\section{INTRODUCTION}

One of the factors that influence the growth rate of fish includes food dispersal system. A small scale aquaculture or highly invested aquaculture project need to deliberate this feeder machine related to the income profit [1]. Nowadays there are several fish food distributions systems was developed by researcher. In April 1999, Anthony Cristopher Halford is the first researcher was developed an automatic fish feeder system under intellectual pattern. The machine has been upgraded by Chang et. al. in 2005 by installing Programmable Logic Controller (PLC) as a main controller [2]. In 2007, Ho et. al. was developed an automatic fish feeder machine and used a microcontroller to generate $12 \mathrm{~V} \mathrm{DC}$ motor at full speed [3].

DC motor are mostly used in industrial field which is in robotic control systems, transportation control system and other applications due to their dynamic and efficiency characteristics compatible with most mechanical loads [4]. The performance of the DC motor system may be influenced by some possibilities which is changes in load dynamic, variable, disturbance and unpredictable inputs, unknown parameters. Therefore, the motor must be analysed and controlled [5].

There are several researches that emphasized on application and analysis of DC motor. The measured data which comprise input and output as experimental dataset were used to develop a DC motor model bye identification process. Ye Naung et. al., 2018, implemented data driven approach to be used in system identification process and controlled a system DC motor-based. In this research, DC motor is a hardware part where the data input voltage and output speed have been recorded. The recorded data is used to execute system identification process by using basic modelling similar with real DC motor by using simscape electronic system to obtain the data of input voltage and output speed of DC motor. This research is to identify the system using toolbox and nonlinear autoregressive with exogenous input (NARX) neural 
network. The input voltage and output speed were measured from the dc motor which also known as actuator [6].

\section{SYSTEM DESCRIPTION}

The structure of feeder machine consists of two parts. The first part used a storage which can put up to $5 \mathrm{~kg}$ pallet. At this part, the drop mechanism uses silicone blades before the pallet spread into channels by four blades. The distribution blade is driven by a 12 Volts DC Geared motor equipped encoder with maximum speed $265 \mathrm{RPM}$ and $3 \mathrm{~kg} / \mathrm{cm}$ torque. The speed range of $255 \mathrm{PWM}$ was used to drive the distribution blade and push out the fish pallets into targeted area which is pond or cages. The machine was also powered by Arduino microcontroller to give commands to DC Geared motor that attached on dispenser and distribution part through motor driver. However, the DC Geared motor on distribution process during motion and friction with its contact on the DC geared motor at distribution part. Figure 1 shows the real setup of the machine.

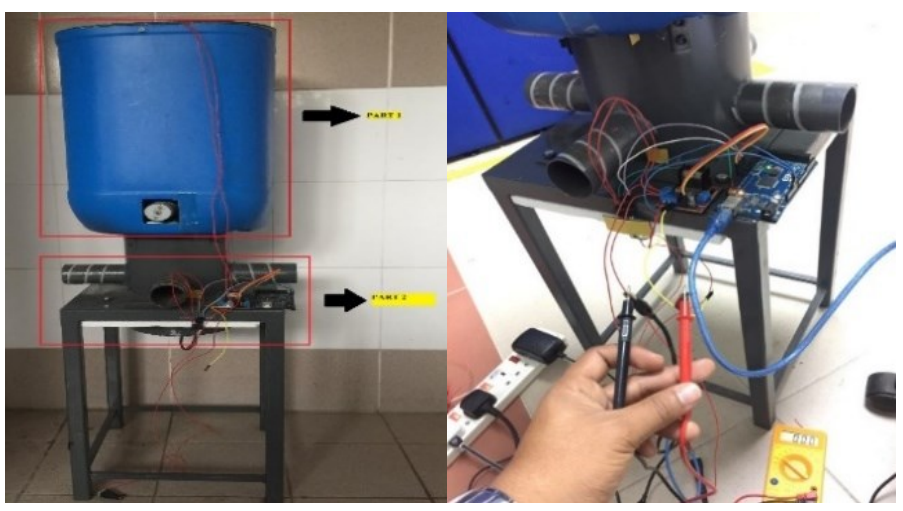

Figure 1. Automatic fish feeder machine and experimental setup

\section{EXPERIMENTAL DATASET}

The feeder system can be represented by determining the input and output by experimental set his section, it is explained the results of research and atand develop the model as close as its system. In this research, the experiment process was conducted on DC geared motor. The experiment purpose is to obtain input and (voltage) and output (speed). Then, the recorded data will be used for system identification process to build the model of the system. This identification process is intended to generate a transfer function in the form parametric model which is ARX (autoregressive with external input) model.

Figure 2 described the experiment setup to measuring the input voltage of DC geared motor. DC motor has been tested by setting the value of PWM 150 as minimum and 255 is maximum with scale increase 1 . The voltage sensor has been used to determine the voltage produced by DC motor.

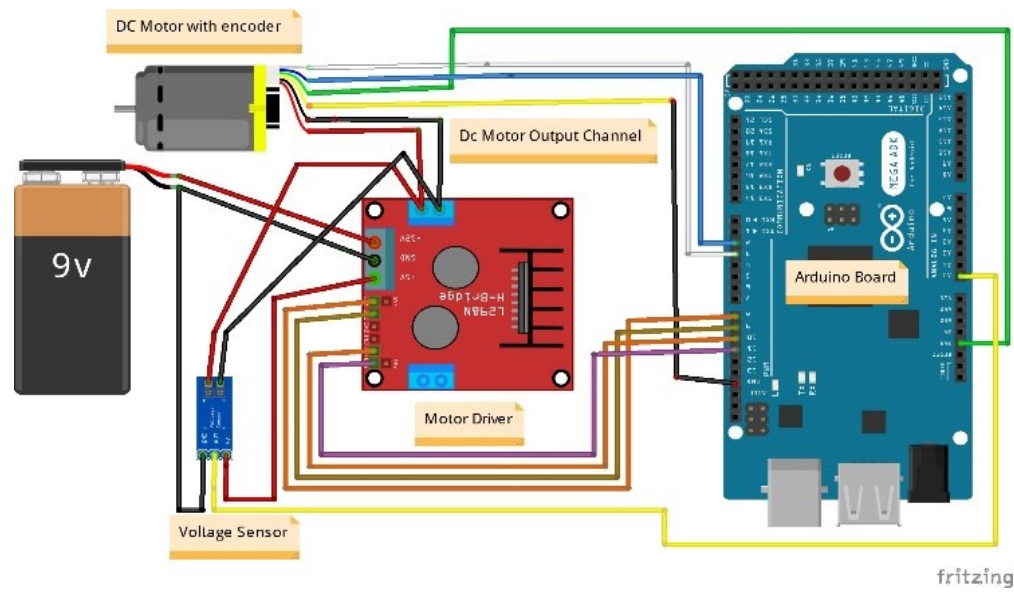

Figure 2. An illustrated of equipment setup to record the input voltage

Experimental dataset to develop a parametric model based of DC geared motor in feeder... (Azlan, W. M.) 
Firstly, the machine was switched on. Then the voltage sensor was used to measure the voltage value of DC geared motor. The workspace recorded the real-time voltage reading.

In recording the output speed of DC motor, Matlab/Simulink was used to construct algorithm for interfacing the machine and Arduino controller as shown in Figure 3. In this experiment, DC motor is turn ON for 20 seconds for each PWM which in range 150-255.
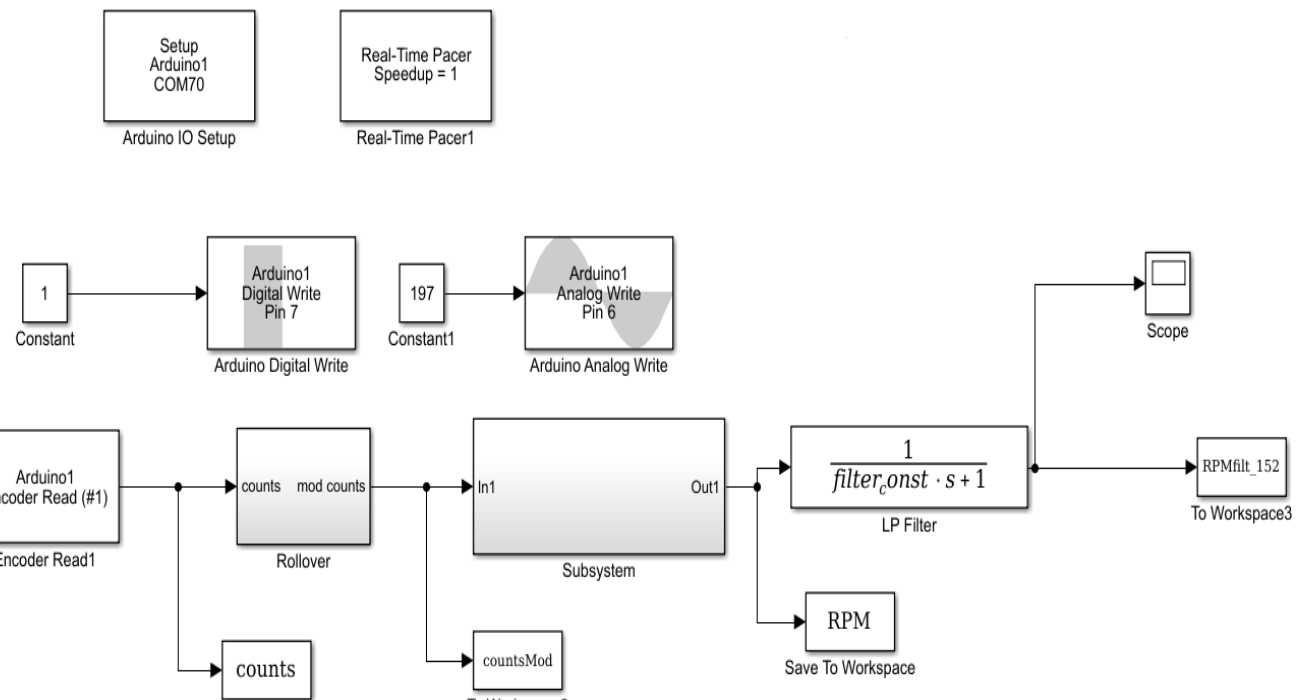

Figure 3. Matlab/Simulink configuration

\section{PARAMETRIC MODELLING}

System identification encompasses parametric models of dynamical system using input and output data of the system [7]. The flowchart to develop dynamic model using system identification is shown in Figure 4. Based on Figure 4 above, there are four basic steps to develop the model. After the experiment and recording of dataset as in experiment section, a parametric model structure need to determined.

A parametric model structure is also known as a black box model, which determines continuous or discrete time system. The principle of system identification based on parametric model is to create mathematical models guided by actual data.

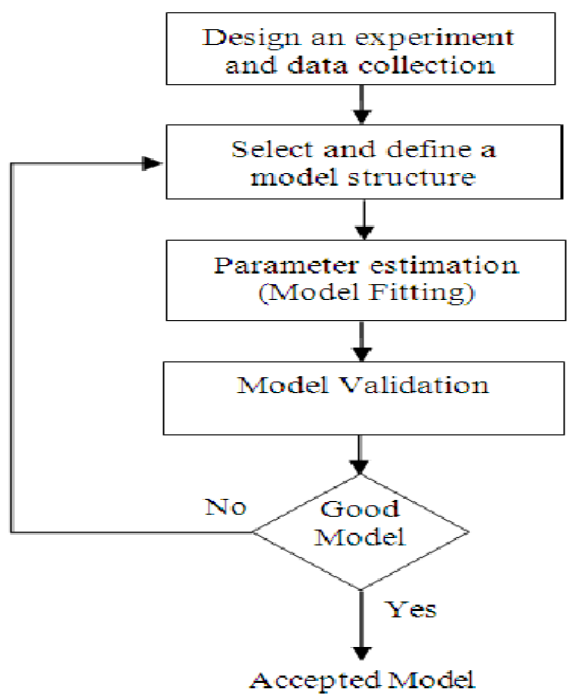

Figure 4. The flow of system identification process [8] 
ARX ARMAX model can be used as a representative for a particular system. This research used ARX model in the methodology. The ARX model structure is simple in parametric structure which can be return in (1):

$$
A\left(q^{-1}\right) y(k-n)=q^{-d} B\left(q^{-1}\right) u(k-n)+e(k)
$$

$A\left(q^{-1}\right)$ and $B\left(q^{-1}\right)$ are polynomial to be estimated. For the ARX the polynomial $C\left(q^{-1}\right)=1$. These polynomials represent the overall dynamical systems where (2) and (3) are defined as follow:

$$
\begin{aligned}
& A\left(q^{-1}\right)=1+a_{1} q^{-1}+\cdots+a_{n a} q^{-n a} \\
& B\left(q^{-1}\right)=b_{0}+\cdots+b_{n b} q^{-n b}
\end{aligned}
$$

$u(k)$ and $y(k)$ represent the input and output of the systems and $e(k)$ is a white noise signal, $\mathrm{k}$ is time unit and $\left(q^{-1}\right)$ represent the delay operator. Variables $a_{i}, b_{j}$, are the model parameters to be estimated, with $i=$ $1, \ldots . n_{a}, j=1, \ldots . n_{b}$. The minimum value of $n$ is supposed to be equal to 0 .

\subsection{Particle swarm optimization (PSO)}

Particle Swarm Optimization (PSO) is the evolutionary technique (a search method based on a natural system) was developed by Kennedy and Eberhart [9]-[14]. The system initially had random selective populations. Each solution is potentially called particles while each particle is given a random velocity and flown through the problem space. The particles have memory and each particle tracks the previous best position called ( $\mathrm{P}$ _best) and the corresponding fitness. There are a number of ( $\mathrm{P}$ best) for their respective particles in swarm and the greatest fitness is called the global best, $(\mathrm{G}$ _best $)$ of the swarm. The basic concept of PSO technique is located in accelerating each particle towards the ( $\mathrm{P}$ best) and ( $\mathrm{G}$ best) location, with a random weight acceleration at each step. The equation used in particle swarm optimization as follows (4) and (5):

$$
\begin{aligned}
& V_{i d}=\omega \times V_{i d}+C_{1} x \times\left(P_{g d}-X_{i d}\right)+C_{2} \times \operatorname{rand}_{2} \times\left(P_{g d}-X_{i d}\right) \\
& X_{i d}=X_{i d}+V_{i d}
\end{aligned}
$$

where $X_{i d}$ and $V_{i d}$ represent the velocity and position of the ith particle with $d$ dimensions respectively. Rand $_{1}$ and rand 2 are two uniform random functions, and $\omega$ is the inertia weight, early selected.

PSO has many parameters and this is illustrated as follow: called inertia weight that controls exploitation and exploration of search space cause dynamically adjust velocity $V_{\text {max }}$ is the maximum allowable velocity for the particles for the example, "in this case where the velocity of the particles exceeds $V_{\max }$, then it is limited to $V_{\max }$ ". Therefore, the resolution and fitness of search depending on $V_{\max }$. If the $V_{\max }$ is too high, then the particles will move beyond a good solution. If the $V_{\max }$ is too low, the particles will be trapped in local minima. The value $C_{1}$ and $C_{2}$ constants in (4) and (5), each are referred to as cognition and social components. Figure 5 shows the general flow chart of the PSO algorithm.

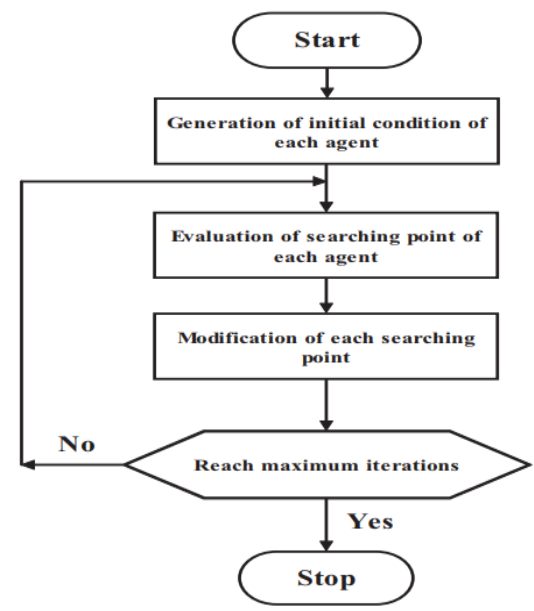

Figure 5. The general flow chart of the PSO algorithm 
In optimization process there is criteria to minimize all of parameter. In this research, the estimated model is based on the criteria of mean square error (MSE) value. The parameter estimation principle as show in Figure 6.

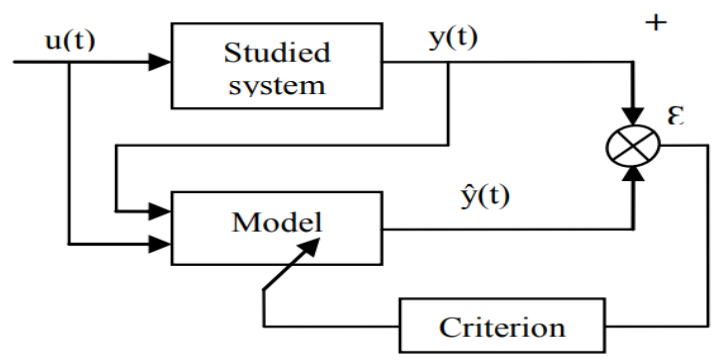

Figure 6. Parameter Estimation Based on MSE

\subsection{Validation model}

The final step of the system identification process is validation model. The measured and desired data is used in validation process. It is the difference between the values estimated by estimator and the true value of quantity being estimated. The lower the value of MSE, the lower the value of error. MSE shows the cumulative square error between the original and reconstructed image. The MSE equation can be written in (6).

$$
M S E=\sum \frac{\left[I_{1}(m, n)-I_{2}(m, n)\right]^{2}}{M * N}
$$

\section{RESULT}

The result will include dataset of input and output response and the parameters from trials using PSO algorithm. Figure 7 show the performance response of the input voltage. The graph shows the increase the value of PWM, the increase the voltage produced.

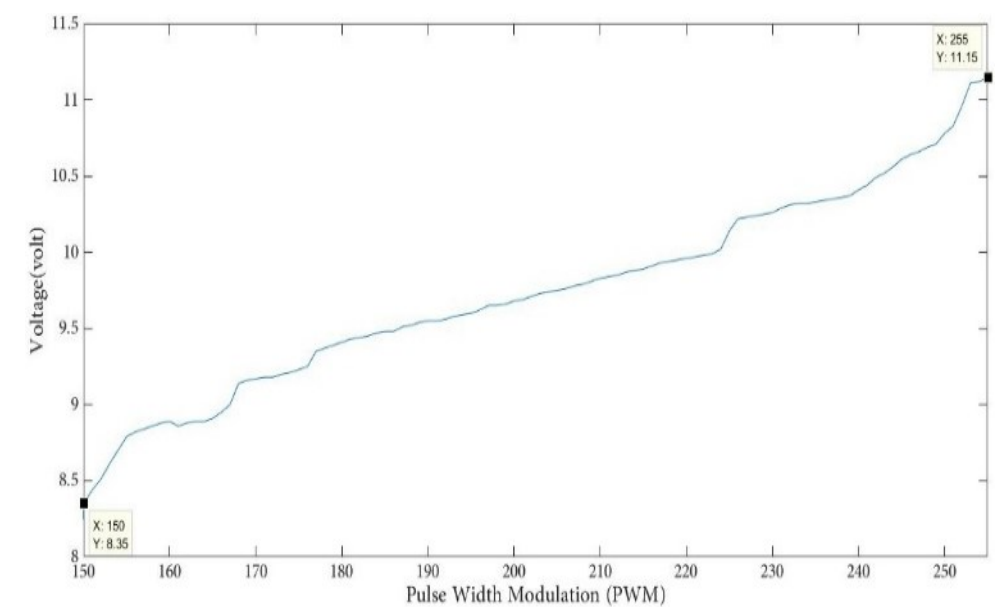

Figure 7. The respond of voltage versus PWM

The experiments had been carried out from different PWM and speed response had been recorded as Figure 8 . All of the data which represented the system will be proceeded to develop the model. 


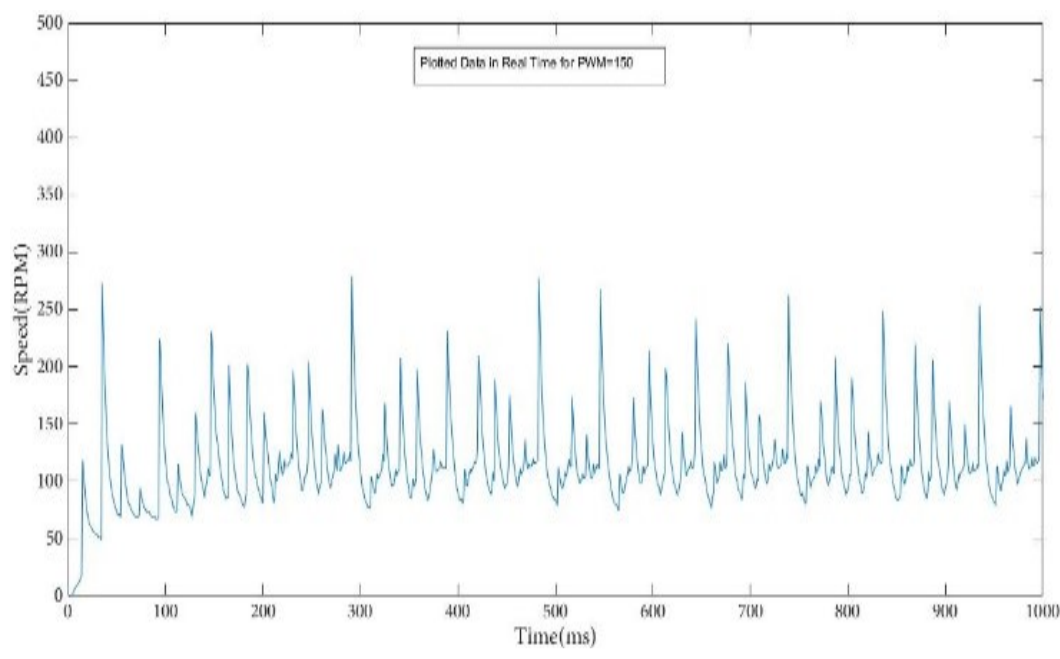

(a) $\mathrm{PWM}=150$

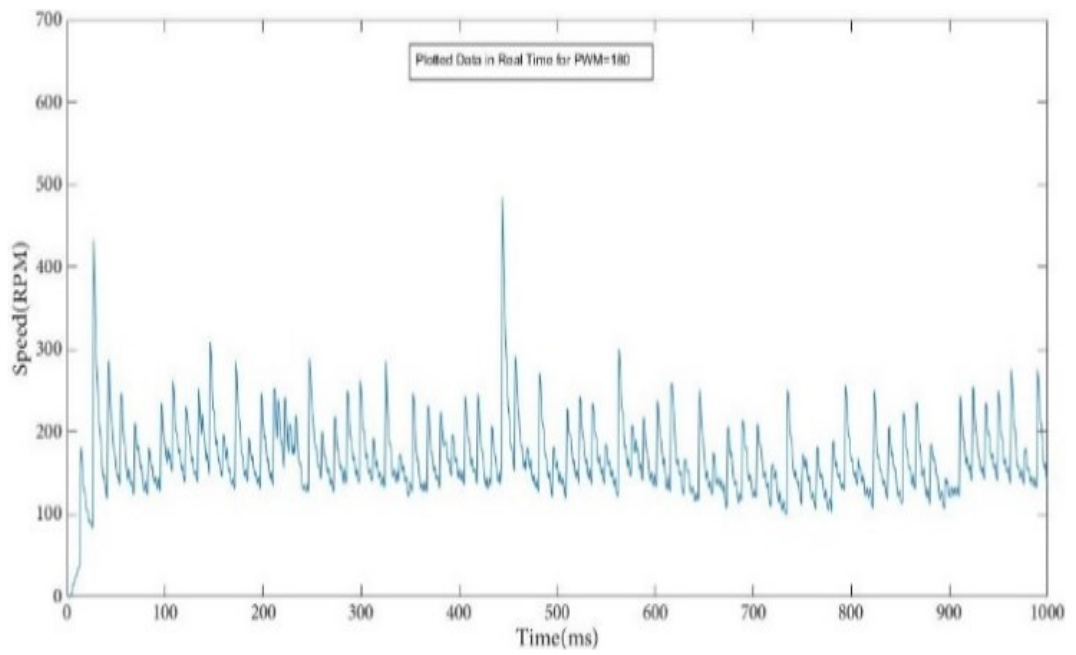

(b) $\mathrm{PWM}=180$

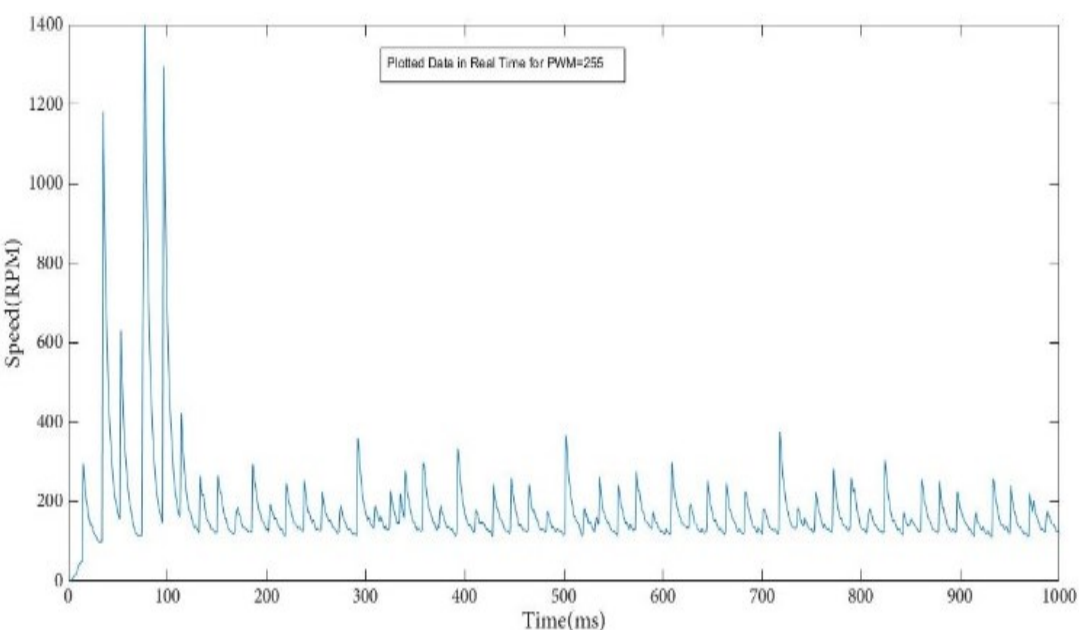

(c) PWM-255

Figure 8. Real time response speed data with different PWM 
After the recording the complete data of voltage and speed of DC motor, the data are used to operate the system identification process. Figure 9 below shown the response voltage and spee of the DC motor.

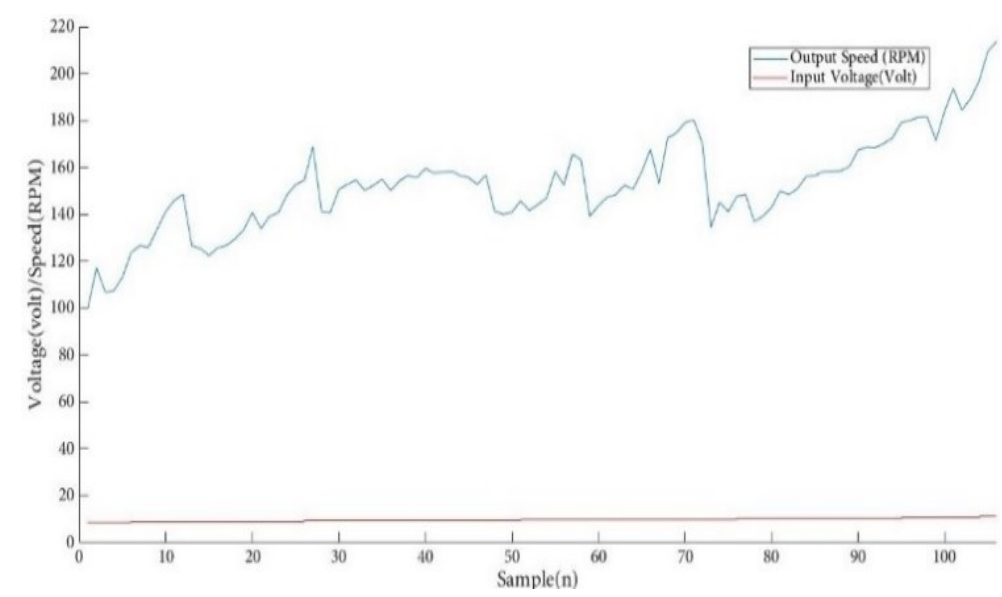

Figure 9. The response input (voltage) and output (speed) of DC motor

In this case, the input and output data will be exporting into the PSO algorithm. After the system identification process based on PSO algorithm complete, the best model was generated with the following validation. Figure 10 shows the ten trial of convergence pattern using PSO optimization. PSO algorithm generated tens model and the best model will be selected based on the several parameters which is time, mean square error (MSE), iteration and average of times. Table 1 shows the result of all the model that have been generated.

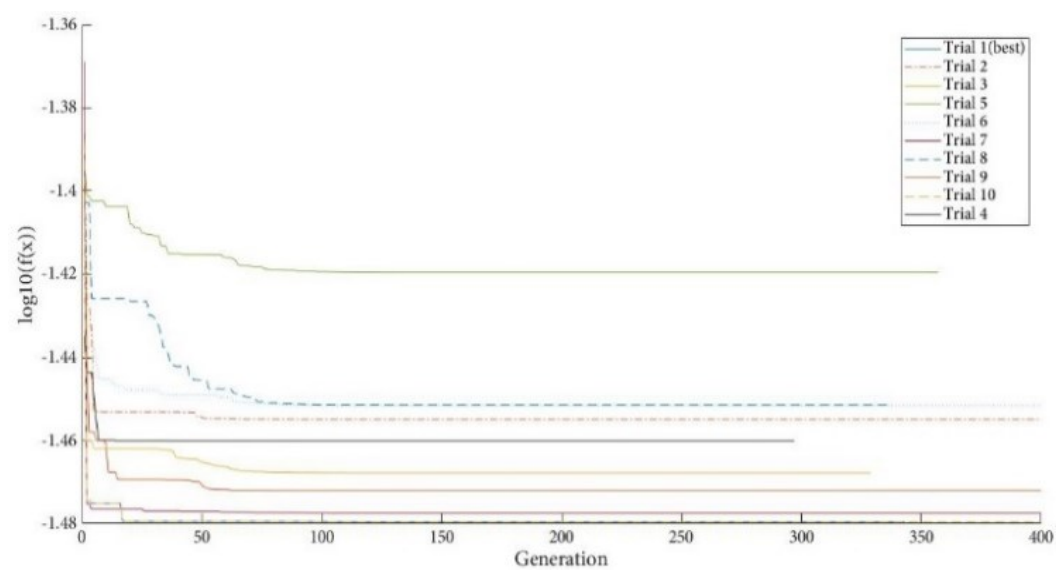

Figure 10. The convergence graph

Table 1. Parameters of 10 Trials

\begin{tabular}{ccccc}
\hline Trial & Time $(\mathrm{s})$ & Final MSE & Iteration & Av. Time \\
\hline 1 & 153.74 & 0.033142 & 343 & 0.4482 \\
2 & 189.49 & 0.035082 & 400 & 0.4737 \\
3 & 161.71 & 0.034058 & 329 & 0.4915 \\
4 & 142.35 & 0.034663 & 297 & 0.4793 \\
5 & 172.75 & 0.038058 & 357 & 0.4839 \\
6 & 195.52 & 0.035354 & 400 & 0.4888 \\
7 & 189.41 & 0.033307 & 400 & 0.4735 \\
8 & 156.6 & 0.035364 & 336 & 0.4661 \\
9 & 190.27 & 0.033728 & 400 & 0.4757 \\
10 & 190.51 & 0.033142 & 400 & 0.4763 \\
\hline
\end{tabular}


Based on the result obtained in the Table 1 and convergence of MSE in each trial a shown in Figure 10, the most suitable model is the first trial with the lowest recorded time is 153.74 seconds, lowest mse is 0.033142 , number of iteration is 343 and total average time is 0.4482 seconds. The best selected model as given in (7).

$$
Y(s)=\frac{2.483 s-1902}{S^{2}+41.4 s+6192}
$$

\section{CONCLUSION}

In this paper, the parametric model for fish feeder system was developed based on measured data input (voltage) and output (speed). Ten trials have been simulated to obtain the best model from dataset of DC geared motor using system identification based on PSO algorithm approach as ARX model. Therefore, the first trial has generated the best model based on the recorded time value of the lowest is 153.74 seconds, the lowest MSE is 0.033142 , and the lowest average time value is 0.4482 seconds. The developed model with minimum means squared error has been achieved and to be proceeded for controller design in future study.

\section{ACKNOWLEDGEMENTS}

This research is supported by the Pascasiswazah (GPPS) grant UTHM.RMC.600-5/1/10(98). Project Vot. Number U967, under Research Management Centre (RMC), University of Tun Hussein Onn Malaysia.

\section{REFERENCES}

[1] FAO, "The State of World Fisheries and Aquaculture 2016: Contributing to Food Security and Nutrition for All," Rome, 2016.

[2] National Plan of Action for Management of Fishing. (2015)

[3] F. Huntingford, M. Jobling \& S. Kadri, “Aquaculture and Behavior,” Wiley-Blackwell, 2012.

[4] Chang, C. M., Fang, W., Jao, R. C., Shyu, C. Z., \& Liao, I. C., "Development of an Intelligent Feeding Controller For Indoor Intensive Culturing of Eel, ” Aquacultural Engineering, vol. 32, no. 2, pp. 343-353, January 2005.

[5] K.W. Hor, S.M Salleh, Abdullah, Mohd Ezree, Zaman, I., M.H. Hatta, S. Ahmad, A.E Ismail, W.A.W Mahmud, "Improvement of Automatic Fish Feeder Machine Design," Journal of Physics: Conference Series, vol. 914, no. 1, 2017.

[6] D.G. Sendrescu, "DC Motor Identification Based on Distributions Method," Ann. Univ. Craiova, vol. 9, no. 36, pp. 41-49, 2012.

[7] Y. Naung, A. Schagin, H. L. Oo, K. Z. Ye and Z. M. Khaing, "Implementation of data driven control system of DC motor by using system identification process," IEEE Conference of Russian Young Researchers in Electrical and Electronic Engineering (EIConRus), Moscow, pp. 1801-1804, 2018.

[8] C. Agarwal and A. Gupta, "Modeling, simulation based DC motor speed control by implementing PID controller on FPGA," Confluence 2013: The Next Generation Information Technology Summit (4th International Conference), Noida, pp. 467-471, 2013.

[9] L.Jung, "System Identification," Technical report, Wiley Encyclopedia of Electrical and Electronics Engineering, no. LiTH-ISY-R-2809, 2007.

[10] L.Jung, "System Identification: Theory for The User," Prentice Hall, 1999.

[11] J. Kennedy and R. Eberhart, "Particle Swarm Optimization," Proceedings, IEEE International Conf. on Neural Networks, vol. 4, pp.1942-1948, 1995.

[12] Y. Shi and R. Eberhart, "Empirical Study of Particle Swarm Optimization," Proceedings of the 1999 Congress on Evolutionary Computation, Vol. 3, 1999.

[13] R. Eberhart and Y Shi, "Particle Swarm Optimization: Developments, Applications and Resources," Proceedings of the 2001 Congress on Evolutionary Computation, vol. 1, pp. 81-86, 2001.

[14] Y. Shi and R. Eberhart, "Parameter Selection in Particle Swarm Optimization," Proc. Seventh Annual Conf. on Evolutionary Programming, pp. 591-601, 1998. 


\section{BIOGRAPHIES OF AUTHORS}

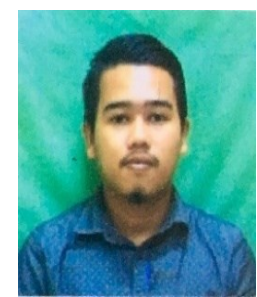

Wan Muhammad Azlan bin W Mahmud is a MEng student and he receives sponsorship from Geran Intensif Penyelidik Siswazah from Graduate Studies Centre UTHM. His research focuses on development of modelling and controlling the feeder system for aquaculture application.

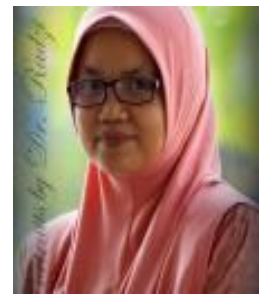

Salihatun Md Salleh is active in modelling using data acquisition and computational numerical methods. She also supervises student in system modelling and control including structure, product design and others. This research is resolve for the problem of grant No. 1081 from Malaysian of Higher Education and grant no. U967 from Universiti Tun Hussein Onn Malaysia specifically for aquaculture development.

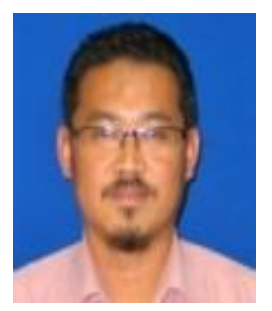

Shahruddin Mahzan is active in composite materials and signal processing application. He also works in intelligent algorithm of neural networks application for mechanical structure.

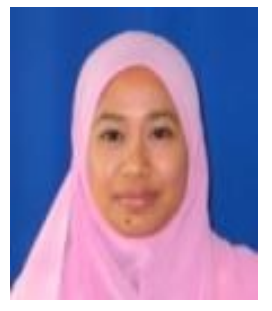

Azmahani Sadikin works on thermal and fluid behaviour of nanofluids and her research interests lie at the heat transfer performance in the heat exchanger using nanofluids. Her research currently focuses on the capability of using nanofluid in solar collector and renewable energy.

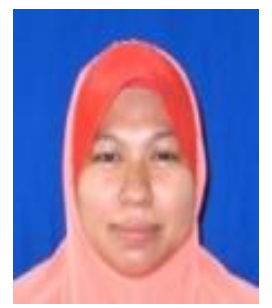

Sufizar Ahmad is active in metal foaming and solid oxide fuel cell application. She also works in ceramic foaming, ceramic foaming, ceramic matrix composite applications and others. 